\title{
THE SEISMIC ISOLATION OF WANGANUI HOSPITAL WITH ROGLIDERS
}

\author{
W.H. Robinson ${ }^{1}$ and C.R. Gannon ${ }^{2}$
}

\begin{abstract}
Two new buildings at Wanganui Hospital, a peri-operative facility and an acute services block, have just been completed in June 2008 using RoGliders to provide seismic isolation in this earthquake prone region. This is the first application of the RoGlider, an isolator suitable for light structures providing in one compact unit the functions of support, damping and the required restoring force, while providing for a maximum displacement of $\pm 400 \mathrm{~mm}$. The RoGlider provides for economical seismic protection under conditions not suitable for lead rubber bearings i.e. a combination of light vertical loads and large horizontal displacements.
\end{abstract}

\section{INTRODUCTION}

In New Zealand, hospital buildings housing buildings emergency related facilities are classed as having a post disaster function and now must be designed to be completely functional after a 1 in 500 year earthquake and also to remain safe after a 1 in 2,500 year event thereby enabling staff and patients to be evacuated safely. An economic way to meet these requirements for light structures is by seismically isolating the buildings with RoGliders ${ }^{\mathrm{TM}}$ (Robinson et al 2004, 2005).

Since the invention of the Lead Rubber Bearing (Robinson \& Tucker 1977), (Robinson 1982) in 1974 and its first application in bridges (1976) and buildings (1981), all in New Zealand, the application of seismic isolation has expanded rapidly with more than 5,000 structures worldwide, the majority isolated by Lead Rubber Bearings (Skinner et al 1993), (Kelly et al 1999) (Robinson 2005), (Kelly et al in press). So far there have been three seismically isolated structures with Lead Rubber Bearings which have been tested in a number of major earthquakes including - University of Southern California Medical Center, Los Angeles (Magnitude 6.7 Northridge (USA) Earthquake, 1994) (Schiff 1995), Bay of Plenty bridge (Magnitude 6.6 Edgecumbe (New Zealand) Earthquake, 1987) a tele-communications building Kobe (Magnitude 6.9 Kobe, (Japan) Earthquake, 1995).

The Lead Rubber Bearing has undergone stringent tests at temperatures as low as $-35^{\circ} \mathrm{C}$ and as high as $45^{\circ} \mathrm{C}$; survived fire for 4 hours, plus many hundreds of cycles representing more than 50 large earthquakes for one Lead Rubber Bearing, fatigue test of 11,000 cycles of an amplitude of $\pm 3 \mathrm{~mm}$

\footnotetext{
${ }^{1}$ Robinson Seismic Ltd, Lower Hutt, New Zealand (Life Member)

${ }^{2}$ Robinson Seismic Ltd, Lower Hutt, New Zealand
}

representing thermal expansion over a 30 year period. The Lead Rubber Bearing has a life expectancy of more than one hundred years and has been thoroughly tested by authorities in NZ, USA and Japan. The Lead Rubber Bearing is most suitable for high vertical loads which correspond to larger cross-sections thereby allowing for large displacements. The horizontal displacement is limited by the stability of the bearing under buckling resulting in a design limitation of approximately half the diameter of the bearing. In tests bearings have safely operated out to displacements greater than their diameters but for safety a conservative approach is taken. Because of this limitation on the Lead Rubber Bearing and the need for a less expensive isolator the RoGlider was developed, that is an isolator which is able to handle large displacements under light vertical loads.

\section{ROGLIDER}

The RoGlider ${ }^{\mathrm{TM}}$ is a sliding bearing which includes an elastic restoring force. The actual configuration is dependent on the details of the structure being isolated and the expected earthquake. The RoGliders for Wanganui are double acting units with the restoring force provided by two rubber membranes (Figures 1 and 2). This double acting RoGlider consists of two flat steel plates with a puck between the plates. The puck consists of alternating layers of rubber and sheet steel, similar to the arrangement used in elastomeric bearings and Lead Rubber Bearings. The sliding elements such as PTFE are mounted at the ends of the puck. This approach enables the RoGlider to be designed to meet specific vertical and rotational (in the vertical plane) stiffnesses. The two rubber membranes are attached to the puck with each being joined to either the top or the bottom 
plates thereby making a sealed unit. When the top and bottom plates slide sideways with respect to each other diagonally opposing parts of the membrane undergo tension or compression. The tension components provide the restoring force between the plates while the compression parts simply buckle and provide little or no restoring force.

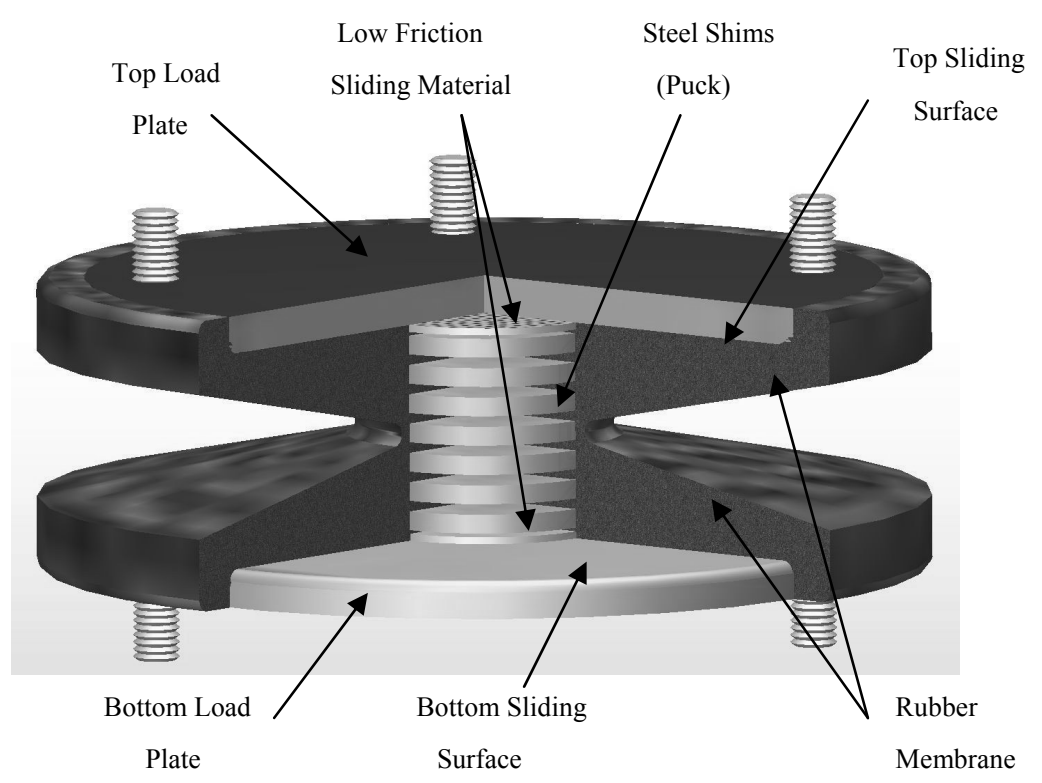

Figure 1. Cross section of RoGlider as used in Wanganui Hospital Buildings.

The resulting RoGlider is a very compact seismic isolator. After a thorough testing program, the first application of the RoGlider is as the seismic isolators for two new buildings in the Wanganui Hospital, 36 beneath a peri-operative building and 48 beneath a acute services wing.

The particular double acting RoGliders for Wanganui Hospital have a maximum displacement of $\pm 400 \mathrm{~mm}$, maximum vertical loads of 200 or $400 \mathrm{kN}$, with an outside diameter of $\sim 650 \mathrm{~mm}$, total height of $156 \mathrm{~mm}$ and a coefficient of friction of $\sim 11 \%$. The period of the building was calculated at $\sim 3$ seconds for the design earthquake. These RoGliders were vulcanised as complete units with the puck and the two plates in place thereby forming a sealed unit providing protection for the sliding surfaces from dust and other extraneous matter. Any rotation in a vertical plane between the top and bottom plates is accommodated by minor deformation of the layers of rubber in the puck.

The RoGlider as manufactured for the Wanganui Hospital Buildings required only one rubber moulding operation resulting in a sealed unit thus enabling costs to be kept to a minimum. The light load of $<100$ tonnes together with the relatively large horizontal displacement of $\sim 400 \mathrm{~mm}$ meant that it was not feasible to use Lead Rubber Bearings. The RoGliders used were compact with a total height of $\sim 156$ mm.

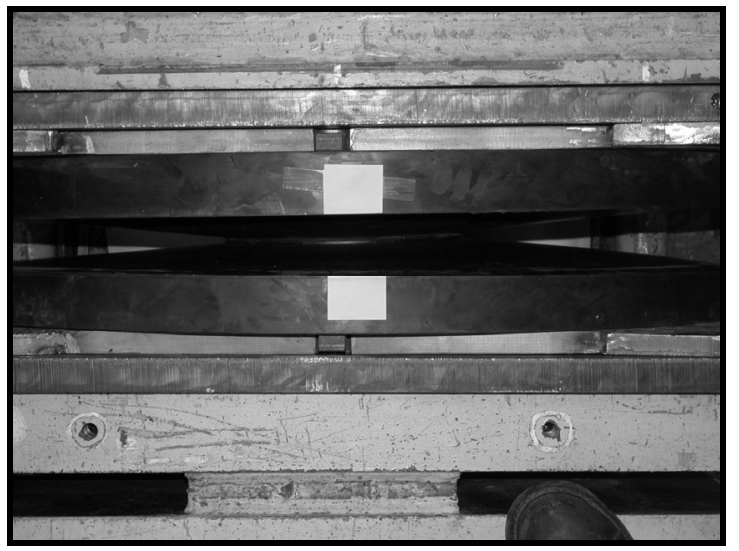

Figure 2a. RoGlider ready for testing. Displacement $0 \mathrm{~mm}$, Vertical force of $850 \mathrm{kN}$.

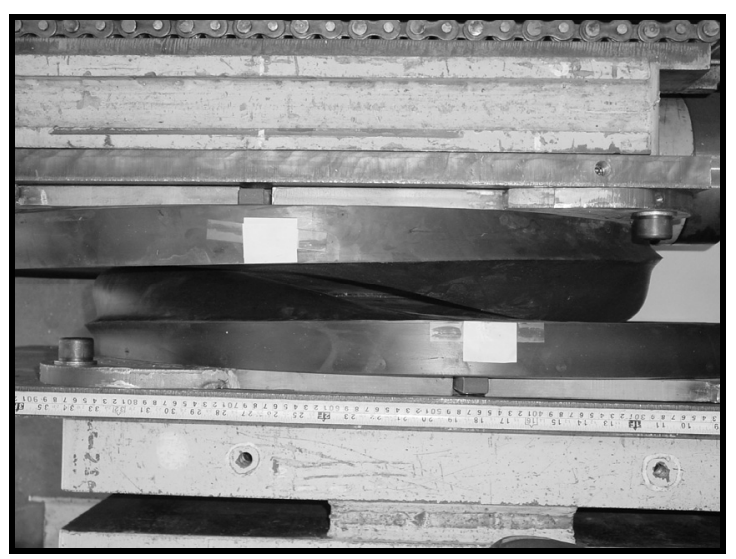

Figure 2b. Prototype RoGlider during test. Displacement $150 \mathrm{~mm}$, vertical force of $850 \mathrm{kN}$. 


\section{TESTING \& TEST RESULTS}

All of the Wanganui Hospital RoGliders had outside diameters of $650 \mathrm{~mm}$ and heights of $156 \mathrm{~mm}$. They carried vertical loads of 20 and 40 tonnes for the peri-operative building and the acute services wing respectively. These seismic isolators were designed for maximum displacements of $400 \mathrm{~mm}$. The isolators were all tested at low speeds $(\sim 1$ $\mathrm{m} / \mathrm{min}$ ) in our small test rig located at Gracefield. Tests on prototype RoGliders at high speeds $(\sim 1 / 4 \mathrm{~m} / \mathrm{sec})$ were carried out using IRL's high speed Instron Test Machine. A typical set of hysteresis loops from a low speed test is shown in Figure 3.

The effective stiffness, $\mathrm{k}(\mathrm{eff})$, for a displacement of $450 \mathrm{~mm}$ for the RoGlider carrying the vertical load of 20 tonnes was measured at $\sim 180 \mathrm{kN} / \mathrm{m}$.

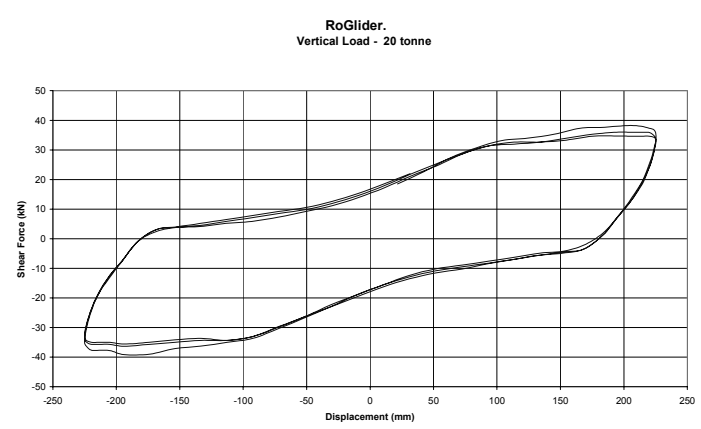

Figure 3. Hysteresis Loop of RoGlider showing vertical load of 20 tonne and displacement of $\pm 250 \mathrm{~mm}$.

\section{DISCUSSION}

A total of 84 RoGliders were manufactured and each one tested before being mounted on piles or columns at the Wanganui Hospital site. The RoGliders were mounted directly on the piles or columns and the building was built directly on top (Figure 4). This approach had the advantage of enabling decisions on placement of most services to be fitted below the new facilities to be held until after the completion of the new buildings.

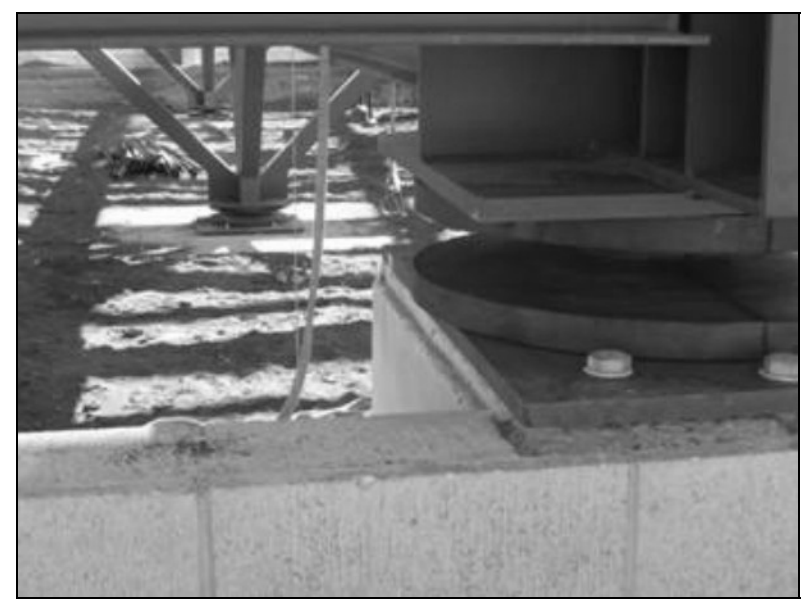

Figure 4. RoGlider installed under the Peri-operative facility at Wanganui Hospital.

\section{CONCLUSIONS}

The RoGlider is an economic Seismic Isolator which supports the structure while providing both the appropriate damping and the required restoring force. Installation is straight forward with the RoGliders being mounted directly on piles or columns and the building built directly on top. In case of the new Wanganui Hospital buildings the RoGlider had a coefficient of friction of $\sim 11 \%$, an outside diameter of $650 \mathrm{~mm}$, a design displacement of $\pm 400 \mathrm{~mm}$ and resulted in an isolation period for the buildings of $\sim 3$ seconds. The effective stiffness, $\mathrm{k}$ (eff), for a displacement of $450 \mathrm{~mm}$ for the RoGlider carrying the vertical load of 20 tonnes was measured at $\sim 180 \mathrm{kN} / \mathrm{m}$. The RoGlider has the great advantage of being extremely compact but also sealed during manufacture resulting in the sliding surfaces being protected from dirt, corrosive atmospheres and liquids. It provides an economical seismic isolation solution under conditions of light vertical load and large horizontal displacement, conditions that are not readily satisfied by more well-known methods of seismic isolation.

\section{ACKNOWLEDGMENT}

The research reported here is supported by Foundation for Research Science and Technology of New Zealand, Contract No C05X0301 via GNS. We would also like to acknowledge the continuing support of the members of the Earthquake Engineering Technology Business Cluster particularly Dr David Hopkins, Dr Richard Sharpe and Graeme Carroll, together with Dr Jim Cousins of GNS.

\section{REFERENCES}

1 Robinson, W.H., \& Tucker, A.G. (1977). "A Lead Rubber Shear Damper". Bulletin of the New Zealand Society for Earthquake Engineering. 10(3), 151.

2 Robinson, W.H. (1982). "Lead-Rubber Hysteretic Bearings Suitable for Protecting Structures during Earthquakes". Earthquake Engineering and Structural Dynamics 10, 593-604.

3 Skinner, R.I., Robinson, W.H. \& McVerry, G.H. (1993). "An Introduction to Seismic Isolation". (Updated and modified in both Chinese and Japanese, 1998). West Sussex: John Wiley \& Sons.

4 Kelly, J.M., Farzad, N. (1999). "Design of Seismic Isolated Structures-From Theory to Practise". New York: John Wiley \& Sons Inc.

5 Robinson, W.H. (2005). "Progress of Application and Research \& Development for Seismic Isolation and Passive Energy Dissipation for Civil and Industrial Structures in New Zealand". Proceedings, $9^{\text {th }}$ World Seminar on Seismic Isolation, Energy Dissipation and Active Vibration Control of Structures, Kobe, Japan, June 13-16 2005.

6 Kelly, T., Skinner, R.I. \& Robinson, W.H. (In Press). "Seismic Isolation for Designers and Structural Engineers".

7 Schiff, A.J. (1995). Northridge Earthquake - lifeline performance \& post earthquake response. Technical Council on Lifeline Earthquake Engineering Monograph, No 8, 339.

8 Robinson, W.H., Meyer, J. \& Gannon, C.R. (2006). "The RoGlider - a sliding bearing with an elastic restoring force." Bulletin of the New Zealand Society for Earthquake Engineering, 39(1), 81-84.

9 Robinson, W.H. \& Gannon, C.R. (2004). RoGlider, PCT/NZ2004/000045. Patents applied for worldwide. 